\title{
Using multiple linear regression technique for predicting the productivity of gypsum plastering works in Buildings
}

\author{
Qais Kadhim Jahanger \\ Environmental Eng. Dep. /Col. of Engineering, Al- Mustansiriayh University, Iraq.
}

Rec. 6 Feb, 2013 Accept. 19 Feb, 2013

\begin{abstract}
Productivity and the need for its development is one of the main challenges that face the construction industry and it is important issue in decision making in the field of construction management. The most reliable measure of productivity is the output per work- time achieved by the labours on construction site. This research aims for developing a model for predicting the productivity of gypsum plastering works for building projects using multiple linear regression techniques. The model was developed based on forty nine set of data collected in Baghdad city from the period (January to June 2012) through observation. In this research, the regression model was developed in four runs by using (MS Excel) program, the result showed that Model four was more fitted model with average accuracy percentage of $(95 \%)$ to predict productivity of gypsum plastering works in buildings.
\end{abstract}

Keywords: Multiple Linear Regression, Productivity, Gypsum Plastering.

\section{Introduction}

Productivity is the ratio of output of required quality to the inputs for a specific production situation; in the construction industry, it is generally accepted as "work output per mantime worked". For example, excavation can be measured in cubic meters per man-hour and plastering can be measured in square meters per man-day. Improved productivity helps contractors not only to be more efficient and profitable; knowing actual productivity levels also helps them to estimate accurately and be more competitive during bidding for projects.

Regression models may be one of the most commonly used statistical analysis techniques in educational research. Typically, regression analysis is used to investigate the relationships between a dependent variable (either categorical or continuous) and a set of independent variables based on a sample from a particular population.

This research presents Multiple Linear regression model that predict the productivity of plastering finishing as a function of seven independent variables. The prediction model is developed based on collected data from 49 work teams in construction projects of building in Baghdad. As these productivity predictions are required at early stages of the project, to estimate finishing duration.

\section{Objective of Research:}

This research aims to develop a model for predicting plastering productivity rate as a function of independent variables from work teams, conditions of building and weather condition.

\section{Research Methodology:}

The research work, undertaken to achieve the research objective, has adopted the following methodology:

1. Problem definition: identifying the variables that affecting the productivity of plastering works

2. Literature survey: covering; scientific references including textbooks, conferences, journals, internet and Iraq virtual scientific library (IVSL) that outlined and discussed the multiple linear regression and plastering subject.

3. Data collection: by direct observation of work teams of plastering worked in several buildings in Baghdad city at different times.

4. Developing the model: using MS Excel program to develop the multiple linear

\footnotetext{
* Corresponding author:

Dr. Qais Kadhim Jahanger

凶Qais19649@yahoo.com
} 
regression model for predicting the productivity of manual plastering works

5. Testing the accuracy: checking the accuracy of the developed model, based on related statistical criterions.

6. Results: explain summary of the results and the conclusions from the research.

\section{Multiple Linear Regression:}

In most research problems where regression analysis is applied, more than one independent variable is needed in the regression model. The complexity of most scientific mechanisms is such that in order to be able to predict an important response (dependent variable), a multiple regression model is needed (Walpole, R.E. et al., 2007).

In general, the dependent variable or response $Y$ may be related to $\mathrm{k}$ independent or regressor variables. Modeled as: (Montgomery, D.C. and Runger, G.C., 2010).

$Y=\beta_{0}+\beta_{1} X_{1}+\beta_{2} X_{2}+\ldots \ldots \ldots+\beta_{k} X_{k}+\epsilon \ldots \ldots$ (1) (Walpole, R.E. et al., 2007; Montgomery, D.C. and Runger, G.C., 2010).

This model is called a multiple linear regression model with $\mathrm{k}$ independent variables (regressor). The parameters $\beta_{\mathrm{j}}, \mathrm{j}=0,1,2, \ldots, \mathrm{k}$, are called the regression coefficients. This model describes a hyper plane in the $\mathrm{k}$ dimensional space of the independent variables $\left\{X_{j}\right\}$. The parameters $\beta_{\mathrm{j}}$ represents the expected change in response $Y$ per unit change in $X_{j}$ when all the remaining regressors $X_{i}(i \neq j)$ are held a constant (Montgomery, D.C. and Runger, G.C., 2010).

Estimating the Parameters (Regression Coefficients):

\section{Least Squares Estimation of the Parameters:}

The method of least squares may be used to estimate the regression coefficients in the multiple regression model, equation (1). Suppose that $\mathrm{n} \square \mathrm{k}$ observations are available, and let $X_{\mathrm{ji}}$ denote the ith observation or level of variable $X_{j}$. the observations are: (Walpole, R.E. et al., 2007; Montgomery, D.C. and Runger, G.C., 2010).

$\left\{\left(X_{1 i}, X_{2 i}, \ldots, X_{k i}, y_{i}\right), \quad i=1,2, \ldots, n\right.$ and $n \square k$
It is customary to present the data for multiple regression in table such as table (1). Where $y_{i}$ is the observed response to the values $X_{1 \mathrm{i}}, \mathrm{X}_{2 \mathrm{i}}$, ........, $\mathrm{X}_{\mathrm{ki}}$, of the $\mathrm{k}$ independent variables $\mathrm{X}_{1}$, $\mathrm{X}_{2}, \ldots, \mathrm{X}_{\mathrm{k}}$. each observation $\left(\mathrm{X}_{1 \mathrm{i}}, \mathrm{X}_{2 \mathrm{i}}, \ldots \ldots \ldots\right.$, $\left.\mathrm{X}_{\mathrm{ki}}, \mathrm{y}_{\mathrm{i}}\right)$ is assumed to satisfy the following equation

$\mathrm{y}_{\mathrm{i}}=\beta_{0}+\beta_{1} \mathrm{X}_{1 \mathrm{i}}+\beta_{2} \mathrm{X}_{2 \mathrm{i}}+\ldots . .+\beta_{\mathrm{k}} \mathrm{X}_{\mathrm{ki}}+\epsilon_{\mathrm{i}}$

or:

$\mathbf{y}_{\mathrm{i}}=\hat{y}_{\mathrm{i}}+\mathrm{e}_{\mathrm{i}}=\mathrm{b}_{0}+\mathrm{b}_{1} \mathrm{X}_{1 \mathrm{i}}+\mathrm{b}_{2} \mathrm{X}_{2 \mathrm{i}}+\ldots . .+\mathrm{b}_{\mathrm{k}} \mathrm{X}_{\mathrm{ki}}+\mathrm{e}_{\mathrm{i}} \ldots \ldots$. (3)

Where $\epsilon_{\mathrm{i}}$ and $\mathrm{e}_{\mathrm{i}}$ are the random error and residual, respectively, associated with the response $y_{i}$ and fitted value $\hat{y}_{i}$.

\begin{tabular}{|c|c|c|c|c|}
\hline $\mathrm{y}_{\mathrm{i}}$ & $\mathrm{X}_{1}$ & $\mathrm{X}_{2}$ & $\cdots$ & $\mathrm{X}_{\mathrm{k}}$ \\
\hline $\mathrm{y}_{1}$ & $\mathrm{X}_{11}$ & $\mathrm{X}_{21}$ & $\cdots$ & $\mathrm{X}_{\mathrm{k} 1}$ \\
\hline $\mathrm{y}_{2}$ & $\mathrm{X}_{12}$ & $\mathrm{X}_{22}$ & $\cdots$ & $\mathrm{X}_{\mathrm{k} 2}$ \\
\hline$\vdots$ & $\vdots$ & $\vdots$ & $\cdots$ & $\vdots$ \\
\hline $\mathrm{y}_{\mathrm{n}}$ & $\mathrm{X}_{1 \mathrm{n}}$ & $\mathrm{X}_{2 \mathrm{n}}$ & $\cdots$ & $\mathrm{X}_{\mathrm{kn}}$ \\
\hline
\end{tabular}

Table (1): Data for multiple linear regression

In using the concept of least squares to arrive at estimates $b_{0}, b_{1}, \ldots, b_{k}$, we minimize the expression

SSE $=\sum_{i=1}^{n} e_{i}^{2}=E_{i=1}^{n}\left(y_{1}-b_{0}-b_{1} x_{4 i}-b_{2} x_{2 i}-\ldots-b_{k} x_{k i}\right)^{2} \ldots(\mathbf{4})$.

(Walpole, R.E. et al., 2007; Montgomery, D.C. and Runger, G.C., 2010).

SSE: Least squares, errors.

Differentiating SSE in turn with respect to $\mathrm{b}_{0}, \mathrm{~b}_{1}, \ldots, \mathrm{b}_{\mathrm{k}}$, and equating to zero, we generate the set of $k+1$ normal estimation equations for multiple linear regression. (Walpole, R.E. et al., 2007). these equations illustrated in most statistical books. one equation for each of the unknown regression coefficients, the solution to the normal equations will be the least square estimators of the regression coefficients $b_{0}, b_{1}, b_{2}, \ldots, b_{k}$ the normal equations can be solved by any method appropriate for solving a system of linear equations. (Montgomery, D.C. and Runger, G.C., 2010).

\section{Matrix Approach to Multiple Linear Regression:}

In fitting a multiple linear regression model, particularly when the number of variables exceeds two, knowledge of matrix theory can 
facilitate the mathematical manipulations considerably. Suppose that the experimenter has $k$ independent variables $X_{1}, X_{2}, \ldots, X_{k}$ and $n$ observations $y_{1}, y_{2}, \ldots, y_{n}$, each of which can be expressed by the equation (1).

$\mathbf{y}_{\mathrm{i}}=\boldsymbol{\beta}_{\mathbf{0}}+\boldsymbol{\beta}_{\mathbf{1}} \mathbf{X}_{1 \mathrm{i}}+\boldsymbol{\beta}_{\mathbf{2}} \mathbf{X}_{2 \mathrm{i}}+. .+\boldsymbol{\beta}_{\mathrm{k}} \mathbf{X}_{\mathrm{ki}}+\square \mathrm{i} \mathbf{i}=\mathbf{1 , 2}, \mathbf{2}$ (Walpole, R.E. et al., 2007; Montgomery, D.C. and Runger, G.C., 2010).

This model is a system of $n$ equations that can be expressed in matrix notations as

$\mathbf{y}=\mathbf{X} \boldsymbol{\beta}$ (5) (Walpole,

R.E. et al., 2007; Montgomery, D.C. and Runger, G.C., 2010).

Where:

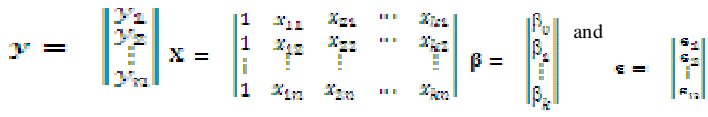

In general, $\mathbf{y}$ is an $(\mathrm{n} * 1)$ vector of observation, $\mathbf{X}$ is an (n* p) matrix of the levels of the independent variables, $\boldsymbol{\beta}$ is a $(p * 1)$ vector of the regression coefficients, and $\square$ is a (n * 1) vector of random errors.( Montgomery, D.C. and Runger, G.C., 2010).

Then the least squares solution for estimation of $\beta$ illustrated previously in section 5.1 involves finding $b$ for which

SSE $=(\mathbf{y}-\mathbf{X b})^{\prime}(\mathbf{y}-\mathbf{X b})$

For minimization process equation 6 is solved for $b$ in the equation

$\frac{\partial}{\partial b}(S S E)=0$

The details regarding solutions of the equations above will not be presented. Techniques for inverting this matrix are explained in most textbooks on elementary determinants and matrices. of course, there are many high-speed computer packages like (SPSS and Excel) available for multiple regression problems. Those Packages not only print out estimates of the regression coefficients but also provide other information relevant to making inferences concerning the regression equations.

\section{Plastering:}

Plaster:- is a wet mixed material applied to internal walls as a finish to fill in any irregularities in the wall surface and to provide a smooth continuous surface suitable for direct decoration. The plaster finish also needs to have a good resistance to impact damage. The material used to fulfill these requirements is gypsum plaster. (Chudely, R. and Greeno, 2006).

Also plastering by gypsum is easy in its mixing and spreading and can do the plastering with least layers and least thickness and also has little initial setting with high speed of rigidity so that gives a smooth surface receiving the paints in excellent shape without any effects on the paints. (Levon, A. and Sako, Z., 2007). In Iraq for the lower layers used the mechanical gypsum (grout) while the technical gypsum used for the surface layer. (Salman, A. J., 1988).

\section{Types of Plastering Works:}

\section{Normal Plastering:}

it done by two layers, the first layer will be to adjust the surface of the wall and the second (surface) layer used for sealing and smoothing the surface, where the thickness of plastering layers about $(20-25) \mathrm{mm}$. ( Levon, A. and Sako, Z., 2007; Salman, A. J., 1988).

\section{Plastering by Ruler:}

in this plastering a gypsum (grout) ruler done in vertical and equilibrium shape for adjusting and straitening the wall surface. These rulers done vertically from the ceiling to the ground levels by fixing Aluminum (or wooden previously) rulers by the plaster material then fill the space between it and the wall by plaster as the thickness of plastering wanted, with distance about $500 \mathrm{~mm}$ between the rulers then removing the aluminum rulers and fill the space between the plaster rulers by the same material then adjusting the wall surface between the plaster rulers to eliminate the increased materials so have $90^{\circ}$ angles in corners and line of intersection among walls and ceiling. While the final layer will done by technical gypsum by thickness about (2-3) mm so we have walls with smooth surface and right angles better from the normal plastering (Levon, A. and Sako, Z., 2007; Salman, A.J., 1988).

\section{Data Collection:}

The estimating technique requires an extensive observed data base. The data has 
been collected from work teams of plastering worked in building projects in Baghdad city, The data that is collected comprised 49 work teams of projects constructed in Baghdad over various conditions by ruler plastering method. The data is tabulated to ensure that all variables are considered, none is doublecounted and all are clearly defined.

A simple checklist is prepared to collect data from the skilled labors by direct observation so record the independents variables that effects on the productivity of work teams, also benefits from historical data of the skilled labors for different conditions of construction. The work teams consist mainly from (skilled labor and labor) with working time $8 \mathrm{hr} /$ day. Table 2. explains the productivity and other variables affecting on it.

\begin{tabular}{|c|c|c|c|c|c|c|c|}
\hline Productivity & Age & Experience & Height of walls & Additional Labor & Weather & Architecture of Building & Site Situation \\
\hline 23 & 37 & 17 & 3.15 & 0 & 3 & 2 & 1 \\
\hline 24 & 30 & 8 & 3.15 & 1 & 3 & 1 & 2 \\
\hline 24 & 50 & 25 & 3 & 1 & 1 & 1 & 2 \\
\hline 23.5 & 27 & 7 & 3 & 0 & 2 & 1 & 1 \\
\hline 22 & 22 & 6 & 3.15 & 0 & 1 & 1 & 1 \\
\hline 22.5 & 24 & 6 & 4 & 1 & 2 & 2 & 2 \\
\hline 19.75 & 20 & 2 & 4.25 & 0 & 1 & 1 & 2 \\
\hline 20 & 20 & 3 & 4.1 & 1 & 3 & 1 & 1 \\
\hline 22.5 & 25 & 6 & 3 & 0 & 2 & 2 & 2 \\
\hline 16.25 & 28 & 8 & 3.15 & 0 & 2 & 3 & 2 \\
\hline 14.5 & 26 & 5 & 3.15 & 0 & 2 & 3 & 2 \\
\hline 24 & 28 & 8 & 3 & 1 & 3 & 1 & 1 \\
\hline 21.5 & 28 & 8 & 6 & 1 & 2 & 1 & 2 \\
\hline 22 & 25 & 5 & 3 & 0 & 1 & 1 & $\frac{2}{2}$ \\
\hline 20.5 & 20 & 3 & 3.1 & 1 & 2 & 2 & 2 \\
\hline 24.5 & 30 & 10 & 3 & 0 & 3 & 1 & 2 \\
\hline 23.5 & 27 & 10 & 3 & 0 & 2 & 1 & 1 \\
\hline 22.5 & 24 & 5 & 3.1 & 1 & 3 & 1 & 2 \\
\hline 22.5 & 27 & 7 & 3.1 & 0 & 2 & 1 & 2 \\
\hline 25 & 31 & 13 & 3.1 & 0 & 3 & 1 & 2 \\
\hline 23 & 35 & 14 & 3.15 & 0 & 2 & 2 & 2 \\
\hline 21 & 21 & 4 & 3.1 & 0 & 3 & 1 & 1 \\
\hline 24 & 40 & 20 & 3.15 & 1 & 3 & 2 & 2 \\
\hline 20 & 19 & 2 & 3 & 1 & 2 & 2 & 1 \\
\hline 22 & 36 & 10 & 3.1 & 1 & 2 & 2 & 2 \\
\hline 24 & 36 & 16 & 3 & 0 & 3 & 1 & 2 \\
\hline 25.25 & 42 & 23 & 3 & 0 & 3 & 1 & 2 \\
\hline 24 & 41 & 20 & 3.1 & 1 & 3 & 1 & 2 \\
\hline 25.5 & 45 & 25 & 3 & 0 & 3 & 1 & 2 \\
\hline 22.5 & 45 & 15 & 3.2 & 0 & 2 & 1 & 1 \\
\hline 21.5 & 37 & 17 & 8 & 1 & 2 & 1 & 1 \\
\hline 21.25 & 24 & 5 & 4.1 & 1 & 3 & 1 & 2 \\
\hline 24 & 28 & 9 & 3 & 1 & 3 & 1 & 2 \\
\hline 24.5 & 32 & 9 & 3.15 & 1 & 3 & 1 & 1 \\
\hline 25 & 34 & 12 & 3 & 1 & 3 & 1 & 2 \\
\hline 21.25 & 33 & 11 & 4.15 & 0 & 1 & 2 & 1 \\
\hline 17 & 34 & 12 & 3.2 & 0 & 1 & 3 & 1 \\
\hline 16 & 35 & 9 & 3.15 & 0 & 2 & 3 & 1 \\
\hline 24 & 37 & 16 & 3 & 0 & 3 & 1 & 2 \\
\hline 23 & 38 & 16 & 3 & 0 & 2 & 1 & 1 \\
\hline 20.25 & 43 & 18 & 3 & 0 & 1 & 1 & 1 \\
\hline 23 & 26 & 5 & 2.9 & 0 & 1 & 2 & 1 \\
\hline 24.5 & 33 & 13 & 3 & 0 & 2 & 1 & 1 \\
\hline 25 & 34 & 15 & 3.1 & 0 & 3 & 1 & 1 \\
\hline 26 & 38 & 22 & 3.1 & 1 & 3 & 1 & 1 \\
\hline 22.5 & 31 & 10 & 3.1 & 0 & 1 & 1 & 2 \\
\hline 21.5 & 37 & 14 & 3 & 0 & 1 & 1 & 1 \\
\hline 21.5 & 28 & 6 & 3 & 1 & 1 & 1 & 1 \\
\hline 20.5 & 20 & 3 & 3.1 & 1 & 2 & 2 & 2 \\
\hline
\end{tabular}

Table. 2: Data collected for gypsum plastering productivity. 


\section{Proposed Model Variables:}

Many qualitative and quantitative variables may affect on the productivity of gypsum plastering for internal finishing of building construction (mostly houses) in this research.

As the objective of this research is to develop a model that can be handled easily using calculators or simple computer programs for predicting plastering productivity of projects, the model is developed based on variables that have significant impact on plastering productivity and that variables identified from observation and discussion with skilled labors.

In this research variables are divided to two main categories:

1. Output (dependent) variable.

2. Input (independent) variables.

Plastering productivity is studied as dependent variable; it is measured by $\left(\mathrm{M}^{2} /\right.$ day), as output calculated from the other input (independent) variables (Age, Experience, Height of Walls, Additional Labor, Weather, Architecture of Building and Site Situation) as shown in table 2 above. The independent variables have been classified to two types:

1. The Quantitative variables.

2. The Qualitative variables.

The quantitative variables consist of four variables:

1. Age: real age for the skilled labor of plastering works, it is measured by numbers (year), and has the symbol $\left(\mathrm{X}_{1}\right)$.

2. Experience: number of experience years of the skilled labor in plastering works, it is measured by numbers (year), and has the symbol $\left(\mathrm{X}_{2}\right)$.

3. Height of walls: maximum height of plastering position from the ground level, it is measured by height units (meter), and has the symbol $\left(\mathrm{X}_{3}\right)$.

4. Additional labor: represents additional labor if needed in the work, it is measured by numbers (man), and has the symbol $\left(\mathrm{X}_{4}\right)$.
While the qualitative variables consist of three variables:

1. Weather: means weather condition in working days of plastering, it is classified to three categories represented by numbers $(1,2,3)$, category of no.(1) represent cold weather, category of no.(2) represent nice weather and category of no.(3) represent hot weather. Has the symbol $\left(\mathrm{X}_{5}\right)$.

2. Architecture of building: represent difficulty degree of interior walls, ceilings and stairs of building for plastering finishing, it is classified to three categories represented by numbers $(1,2,3)$, category of no.(1) represent normal building, category of no.(2) represent modern building and category of no.(3) represent decorated building of special decoration in ceiling and walls. Has the symbol $\left(\mathrm{X}_{6}\right)$.

3. Site situation: represent continuous availability of materials and water in the site, it is classified to two categories represented by numbers $(1,2)$, category of no.(1) represent weak situation and category of no.(2) represent good situation. Has the symbol $\left(\mathrm{X}_{7}\right)$.

\section{Model Development:}

Once the variables to be included in the model have been identified, the model is developed using multiple regression analysis techniques. Regression models are intended to find the linear combination of independent variables which best correlates with dependent variables. The regression equation is expressed simply as follows:

$Y=\mathrm{C}+\mathrm{b}_{1} \mathrm{X}_{1}+\mathrm{b}_{2} \mathrm{X}_{2}+\ldots+\mathrm{b}_{7} \mathrm{X}_{7}$

7

Where,

$\mathrm{C}$ : regression constant

$\mathrm{b}_{1}, \mathrm{~b}_{2}, \ldots, \mathrm{b}_{7}$ : regression parameters

$\mathrm{X}_{1}, \mathrm{X}_{2}, \ldots, \mathrm{X}_{7}$ : independent variables

$Y$ : dependent variable

All variables are significant at the 0.05 level.

\section{Results and Discussion:}

A computer program (MS Excel) (2011; 2009). is used to analysis regression varaibles, a statistical model is developed 
using multiple linear regression technique of (Stepwise Regression: Backward Elimination) (Montgomery, D.C. and Runger, G.C., 2010). Given the observations per project for the predictor variables, the regression model predicted the productivity rate in $\mathrm{M}^{2} /$ day for the plastering works, based on seven statistically significant variables as shown in Table (3).

\begin{tabular}{|c|c|c|c|c|}
\hline \multicolumn{2}{|c|}{ Regression Model } & Variables & Coefficient & P- Value \\
\hline Multiple R & 0.848 & Intercept & 27.011 & $1.78 \mathrm{E}-14$ \\
\hline R square & 0.72 & Age & -0.125 & 0.145 \\
\hline Adjusted R square & 0.672 & Experience & 0.277 & 0.012 \\
\hline Observations & 49 & Height of Walls & -0.654 & 0.014 \\
\hline F & 15.081 & Additional Labor & 0.528 & 0.265 \\
\hline Significance F & $1.47 \mathrm{E}-09$ & Weather & 0.45 & 0.157 \\
\hline & & Architecture of Building & -2.251 & $6.56 \mathrm{E}-08$ \\
\hline & & Site Situation & 0.185 & 0.664 \\
\hline
\end{tabular}

Table 3: Multiple Regression Results among Plastering Productivity variables.

The developed model is:

$\mathrm{Y}=27.108-0.125 \mathrm{X}_{1}+0.277 \mathrm{X}_{2}-0.66 \mathrm{X}_{3}$ $+0.543 \mathrm{X}_{4}+0.466 \mathrm{X}_{5}-2.251 \mathrm{X}_{6}$

$+0.111 \mathrm{X}_{7} \ldots($ Model 1).

It can be seen that the (model 1) has $\mathrm{F} \square$ $\mathrm{F}_{05,7,49}=2.21$ and significance $\mathrm{F}(\mathrm{P}-$ value $)$ is considerably smaller than $\alpha=0.05$, so the model totally is accepted statistically. But four independent variables have $\mathrm{P}$ - value more than $\alpha=0.05$ so they are insignificant, therefore; according to backward elimination (2010; 2009). the independent variable with largest $\mathrm{P}-$ value is eliminated from the model, the statistics results shown in table 4. The developed model is: $\mathrm{Y}=27.297-0.128 \mathrm{X}_{1}+0.28 \mathrm{X}_{2}-0.662 \mathrm{X}_{3}$ $+0.555 \mathrm{X}_{4}+0.469 \mathrm{X}_{5}-2.237 \mathrm{X}_{6} \ldots \ldots$ (Model 2).

\begin{tabular}{|c|c|c|c|c|}
\hline \multicolumn{2}{|c|}{ Regression Model } & Variables & Coefficient & P- Value \\
\hline Multiple R & 0.847 & Intercept & 27.297 & $1.46 \mathrm{E}-15$ \\
\hline R square & 0.718 & Age & -0.128 & 0.134 \\
\hline Adjusted R square & 0.678 & Experience & 0.28 & 0.011 \\
\hline Observations & 49 & Height of Walls & 0.662 & 0.012 \\
\hline F & 17.908 & Additional Labor & 0.555 & 0.233 \\
\hline Significance F & $3.59 \mathrm{E}-10$ & Weather & 0.469 & 0.132 \\
\hline & & Architecture of building & -2.237 & $4.96 \mathrm{E}-08$ \\
\hline
\end{tabular}

Table 4: Regression Results after elimination of site situation variable.

It can be seen from (Model 2) that $\mathrm{F}=$ 17.907 greater than 15.081 in (Model 1) and significance $\mathrm{F}$ is smaller than 0.05 significance level, that means the (Model 2) is better more than (Model 1), but still there are some independent variables have $\mathrm{P}$ value greater than 0.05 significance level.
Therefore to modify the model the independent variable of largest $\mathrm{P}$-value is eliminated from (model 2).

The correlation among dependent variable and independent variables is tested also; the results are shown in Table (5) below. 


\begin{tabular}{|c|c|c|c|c|c|c|c|c|}
\hline & Productivity & Age & Experience & $\begin{array}{l}\text { Height of } \\
\text { walls }\end{array}$ & $\begin{array}{l}\text { Additional } \\
\text { Labor }\end{array}$ & Weather & $\begin{array}{l}\text { Architecture } \\
\text { of building }\end{array}$ & $\begin{array}{l}\text { Site } \\
\text { Situation }\end{array}$ \\
\hline Productivity & 1 & & & & & & & \\
\hline Age & 0.356 & 1 & & & & & & \\
\hline Experience & 0.484 & 0.937 & 1 & & & & & \\
\hline Height of walls & -0.159 & -0.058 & -0.032 & 1 & & & & \\
\hline Additional Labor & 0.13 & -0.132 & -0.112 & 0.272 & 1 & & & \\
\hline Weather & 0.442 & 0.077 & 0.206 & -0.073 & 0.285 & 1 & & \\
\hline Architecture of building & -0.7 & -0.141 & -0.219 & -0.085 & -0.115 & -0.228 & 1 & \\
\hline Site Situation & 0.092 & -0.036 & 0.002 & -0.053 & 0.165 & 0.214 & 0.034 & 1 \\
\hline
\end{tabular}

Table 5: Coefficient of Correlation.

The results of $\mathrm{R}$ (coefficient of correlation) show that the additional labor is a variable of $2^{\text {nd }}$ lowest correlation $(0.13)$ with productivity after site situation, so the regression result of elimination is shown in table 6. The developed model is: $\mathrm{Y}=26.915-0.12 \mathrm{X}_{1}+0.262 \mathrm{X}_{2}-0.568 \mathrm{X}_{3}$ $+0.596 \mathrm{X}_{5}-2.265 \mathrm{X}_{6}$

(Model 3).

\begin{tabular}{|c|c|c|c|c|}
\hline \multicolumn{2}{|c|}{ Regression Model } & Variables & Coefficient & P- Value \\
\hline Multiple R & 0.842 & Intercept & 26.915 & $1.36 \mathrm{E}-15$ \\
\hline R square & 0.709 & Age & -0.12 & 0.159 \\
\hline Adjusted R square & 0.675 & Experience & 0.262 & 0.016 \\
\hline Observations & 49 & Height of Walls & -0.568 & 0.023 \\
\hline F & 20.973 & Weather & 0.596 & 0.045 \\
\hline Significance F & $1.47 \mathrm{E}-10$ & Architecture of building & -2.265 & $3.63 \mathrm{E}-08$ \\
\hline
\end{tabular}

Table 6: Regression Results after elimination of additional labor variable.

It can be seen from (Model) that $\mathrm{F}=$ 20.973 greater than 17. 907 in (Model 2) and significance $F$ is smaller than $\alpha=0.05$, that means the (Model 2) is improved more than (Model 2), but still there is one independent variables have $\mathrm{P}$-value largest than 0.05 significance level. Therefore; the independent variable (age) of largest $\mathrm{P}$ value $(0.159)$ is eliminated from (model 3 ). The statistics result shown in table (7), the developed model is:

$\mathrm{Y}=24.377+0.12 \mathrm{X}_{2}-0.534 \mathrm{X}_{3}+0.73 \mathrm{X}_{5}-$ $2.325 \mathrm{X}_{5}$

(Model 4).

\begin{tabular}{|c|c|c|c|c|}
\hline \multicolumn{2}{|c|}{ Regression Model } & Variables & Coefficient & P- Value \\
\hline Multiple R & 0.833 & Intercept & 24.377 & $2.13 \mathrm{E}-22$ \\
\hline R square & 0.695 & Experience & 0.12 & 0.001 \\
\hline Adjusted R square & 0.67 & Height of Walls & -0.534 & 0.033 \\
\hline Observations & 49 & Weather & 0.73 & 0.011 \\
\hline F & 25.108 & Architecture of building & -2.325 & $1.97 \mathrm{E}-08$ \\
\hline Significance F & $7.17 \mathrm{E}-11$ & & & \\
\hline
\end{tabular}

Table 7: Regression Results after elimination of age Variable.

It can be seen in (model 4) F-test is 25.108 greater than (model 3 ) and significance $F$ is smaller, that means the (model 4) is improved and best fitted for productivity predication and also all independent variables have $\mathrm{P}$-value less than 0.05 level of significance so the model is accepted statistically.

\section{Accuracy of the Model:}

In this research, the following statistical criterions are used to test the accuracy of the developed model:

1. Mean absolute percentage error (MAPE)( Mahamid, I. 2011; Tayman, J. and Swanson, D. V. 1999). 
$A P E=\left(\begin{array}{lll}1 / n & \sum_{i=1}^{n}\left|\frac{A_{i}-F_{i}}{A i}\right| * 100 \% & \ldots . .8\end{array}\right.$

2. Average accuracy percentage (AA\%) (AL-Zwainy, F. M. S. 2012).

$1 \%=100 \%-$ MAPE $\quad \ldots \ldots \ldots \ldots . . .9$

3. The adjusted coefficient of determination (adjusted $\mathrm{R}^{2}$ )

4. The coefficient of correlation (Multiple R)

\section{Where:}

$$
\begin{aligned}
& \mathrm{A}_{\mathrm{i}}=\text { the actual value } \\
& \mathrm{E}_{\mathrm{i}}=\text { the predicted value } \\
& \mathrm{n}=\text { Number of observation }
\end{aligned}
$$

It is explained from Results in table (8) below, that the developed model for predicting productivity by multiple linear regression of high accuracy percentage (95\%) so that indicate the efficiency of the developed model in this research.

\begin{tabular}{|c|c|}
\hline Statistical Criterion & Statistical value \\
\hline $\begin{array}{c}\text { The coefficient of } \\
\text { correlation ( Multiple R) }\end{array}$ & $83.3 \%$ \\
\hline $\begin{array}{c}\text { The adjusted coefficient of } \\
\text { Determination(adjusted } \mathrm{R}^{2} \text { ) }\end{array}$ & $67 \%$ \\
\hline $\begin{array}{c}\text { Mean absolute percentage } \\
\text { error (MAPE) }\end{array}$ & $5 \%$ \\
\hline $\begin{array}{c}\text { Average accuracy } \\
\text { percentage (AA\%) }\end{array}$ & $95 \%$ \\
\hline
\end{tabular}

Table 8: Accuracy Results for the Developed Model

\section{Summary and Conclusion:}

This research aims for developing a model for prediction of productivity of gypsum plastering works in building projects using multiple linear regression techniques. The model is developed based on 49 set of data collected in Baghdad city. Such types of models are very useful, especially in its simplicity and ability to be handled by calculator or a simple computer program. It has a good benefit in predict productivity of the project since the information needed could be obtained easily from skilled labors or scope definition of the projects.

In this research, the regression model is developed in four runs; the last one (Model 4) has F - test (25.108) and very low significance $\mathrm{F}$ (7.17E-11). P - value for independent variables smaller than $\alpha=0.05$, this indicates that the relationship between the dependent and independent variables of that model is good and the predicted values from a forecast model fit with the real-life data. The developed (Model 4) of average accuracy percentage (95\%), and can be written as:

$\mathrm{Y}=24.377+0.12 \mathrm{X}_{1}-0.534 \mathrm{X}_{2}+0.73 \mathrm{X}_{3}-$ $2.325 \mathrm{X}_{4}$

\section{Where:}

$\mathrm{Y}=$ Productivity

$\mathrm{X}_{1}=$ Experience

$\mathrm{X}_{2}=$ Height of Walls

$\mathrm{X}_{3}=$ Weather

$\mathrm{X}_{4}=$ Architecture of Building.

\section{There are some conclusions:}

1. Coefficient of correlation $\mathrm{R}$ is explained high correlation between (Skilled Labor) age and experience (0.937) and that is realistic, so it is better to input one of them in the model to be accepted statistically. Therefore; experience of $\mathrm{P}$ value less than 0.05 is remained.

2. Site situation for most building observed is good because the availability of materials and water so is became of $\mathrm{P}$ value greatest than 0.05 , therefore; it is eliminated from the model, also additional labor because most work teams consist mainly from (skilled labor and labor).

3. Winter cold weather affecting negatively on plastering productivity due to low degree of mixing water, short duration of day, and humidity and darkness of rained days.

4. Very height walls reduces partially productivity of work team (Skilled worker and semi skilled worker) and needing additional labor often, also a lot of doors, windows and other holes and opened corners and curves in the walls, and unadjusted walls was affecting negatively on plastering productivity of work teams.

5. Modern and decorated buildings (mostly houses) of curved walls and stairs, open corners and decoration in walls and 
ceilings needs more time than normal building of straight regular walls. While site situation for most building is good because the availability of materials and water

\section{References:}

Walpole, R.E. et al.," Probability \& Statistics for Engineering \& Scientists", $8^{\text {th }}$ ed., Pearson Prentice Hall, (2007).

Montgomery, D.C. and Runger, G.C.," Applied Statistics and Probability for Engineers", $4^{\text {th }}$ ed., John Wiley \& Sons, reprinted (2010), India.

Chudely, R. and Greeno," Building Construction Handbook", $6^{\text {th }}$ ed., Butterworth-Heinemann publications, (2006), USA.

Levon, A. and Sako, Z.," Building Construction", Baghdad University, College of Engineering, Reprinted (2007), Iraq.(In Arabic)

Salman, A. J.," Building Combining: Bearing Walls and its Architectural Details", $2^{\text {nd }}$ ed., the Iraqi Company for printing, (1988), Iraq. (In Arabic)

“A Quick Guide to Using Excel 2007's: Regression Analysis Tool" Duke University, the Fuqua school of business, electronic [PDF]. 11/9/(2011).

http://faculty.fuqua.duke.edu/ pecklu nd/ExcelReview/Use\%20Excel\%2020 07\%20Regression.pdf

"Multiple Linear Regression" The Industrial Engineering and Management notepad, 7/9/(2009). (In Arabic)

http://samehar.wordpress.com/(2009)/ 09/07/010909/

Mahamid, I.," Early Cost Estimating for Road Construction Projects Using Multiple Regression Techniques", Australasian Journal of Construction Economics and Building, Vol.11 No. 4, (2011).

Tayman, J. and Swanson, D. V.," On the Validity of MAPE as a Measure of Population Forecast Accuracy", Population Research and Policy Review 18, Kluwer Academic Publishers, (1999), Netherlands.(from Iraqi virtual scientific Library).

AL-Zwainy, F. M. S.," The Use of Artificial Neural Networks for Productivity Estimation of finishing Stone works for Building Projects", Journal of Engineering and Development, Vol.16 No.2, Julay-(2012). (In Arabic).

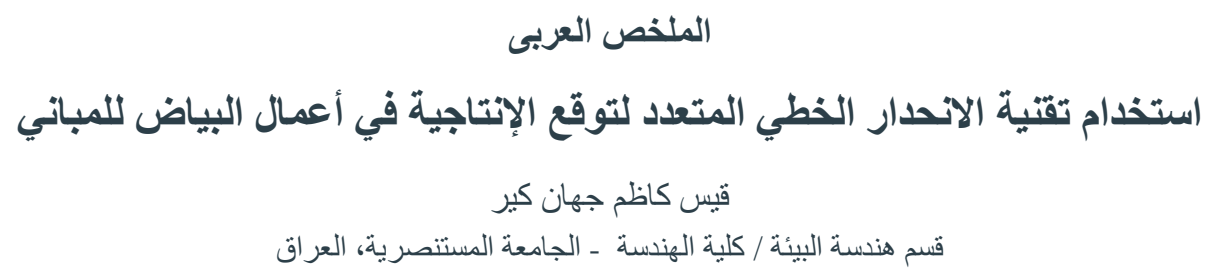

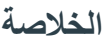

تعد الإنتاجية و الحاجة لتطوير ها أحد التحديات الرئيسة التي تو اجه قطاع البناء و التشييد و عنصر مهر في اتخاذ القرار ضمن

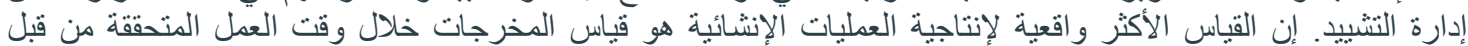

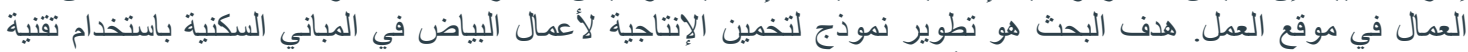

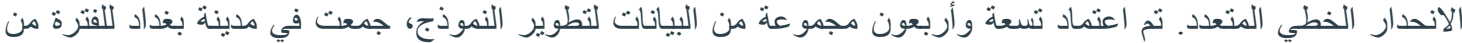
(كانون الثاني لغاية حزير ان 2012 من خلال المشاهدة. (MS Excel)، النموذج الر ابع هو الأكثر ملائمة كمعادلة لتخمين الإنتاجية لأعمال البياض بدرجة خدة دقة مقدار ها (95\%). 